\title{
LIDERANÇA E COMPORTAMENTO ORGANIZACIONAL: Um estudo de caso no sistema carcerário
}

\author{
Maria Letícia Oliveira MARQUES ${ }^{1}$ \\ Daniela Fernanda de Freitas SOUZA ${ }^{2}$ \\ André Luiz Pereira MORI ${ }^{3}$
}

\begin{abstract}
${ }^{1}$ Discente, curso de Especialização MBA em Gestão de Recursos Humanos da Faculdade Santo Agostinho. leticiamarques@yahoo.com.br;

${ }^{2}$ Docente, Faculdade de Ciências e Tecnologias de Campos gerais, Curso de Graduação em Farmácia Generalista. danielaffreitas@bol.com.br;
\end{abstract}

${ }^{3}$ Docente, curso de Especialização MBA em Gestão de Recursos Humanos da Faculdade Santo Agostinho. alpmori@yahoo.com.br

Recebido em: 27/11/2014 - Aprovado em: 03/06/2015 - Disponibilizado em: 15/07/2015

Resumo. As organizações são compostas de pessoas e dependem delas para alcançar seus objetivos e cumprir sua missão. A liderança tem um papel importante no comportamento da equipe, pois o líder orienta e desenvolve a equipe para alcançar os objetivos em comum, e é capaz de influenciar as outras pessoas a ajudar a ampliar estes objetivos, bem como executar e atingir seus próprios desejos e ideais como líder. O presente trabalho objetivou analisar a influência do líder no comportamento organizacional do sistema carcerário de Montes Claros, identificando os estilos de liderança que o líder possui, e como o líder pode influenciar no comportamento das pessoas ao alcance de objetivos dentro da empresa. Para atender estes objetivos utilizou como metodologia a pesquisa de base qualitativa e quantitativa e o método de procedimento foi o estudo de caso. Os dados foram coletados a partir da aplicação de questionários aos funcionários e entrevista aos líderes. A pesquisa atingiu os objetivos pretendidos e demonstrou que a forma como os líderes trabalham é satisfatória, entretanto alguns aspectos precisam ser melhorados.

Palavras-chave: Liderança; Comportamento Organizacional; Estilos de Liderança.

\begin{abstract}
Organizations are made up of people and rely on them to achieve their goals and fulfill its mission. Leadership has an important role in the team's behavior, as the leader directs and develops the team to achieve common goals, and is able to influence other people to help expand these goals as well as perform and achieve their own desires and ideal as a leader. This study aimed to analyze the influence of the leader in organizational behavior in the prison system of Montes Claros, identifying leadership styles that the leader has, and how the leader can influence the behavior of people to reach goals within the company. To meet these goals used as a methodology to qualitative and quantitative research base and the method of procedure was the case study. Data were collected from questionnaires to employees and interview the leaders. The research achieved the desired objectives and demonstrated that how leaders work is satisfactory, however some aspects could be improved.
\end{abstract}

Keywords: Leadership; Organisational Behaviour; Leadership Styles. 


\section{INTRODUÇÃO}

As organizações precisam de pessoas motivadas e com um melhor desempenho, sendo assim surge à necessidade da liderança nas organizações. Para isso é relevante a interação dos líderes com os colaboradores e através desse envolvimento que surge o empenho entre os colaboradores em suas tarefas trazendo para a organização um resultado melhor. $^{1-2}$

O convívio das pessoas que compõem a organização é justificada quando se leva em consideração vários fatores, bem como o clima organizacional e a cultura que se faz presente no dia-a-dia dos colaboradores. Com a cultura influenciando nos costumes e comportamentos do grupo ou da sociedade, cada organização vem desenvolvendo sua cultura.

A liderança e um dos fatores importantes dentro das organizações, o sucesso da empresa pode muitas vezes estar nas atitudes do gestor, ao longo do trabalho será mostrado o estilo de liderança exercido na empresa pesquisada. $^{3}$

\section{MATERIAIS E MÉTODOS}

\section{Tipo de pesquisa}

A pesquisa foi desenvolvida a partir de uma pesquisa bibliográfica que segundo Gil
O objetivo principal desse artigo foi analisar a influência do líder no comportamento organizacional no sistema carcerário de Montes Claros - MG. Um ponto importante está relacionado com a capacidade de influência que o líder tem sobre as pessoas, buscando meios de conseguir um bom desempenho nas suas funções de líder e nos resultados dos seus liderados. Os líderes são aqueles que ocupam uma posição de poder no meio de um grupo e conseguem influenciar com decisões estratégicas as pessoas que o contem. ${ }^{4}$

Os objetivos específicos desse trabalho foram: identificar o perfil dos funcionários da empresa, compreender a importância do papel do líder, identificar o estilo de liderança exercido pelo líder e compreender o comportamento organizacional da empresa.

A escolha do assunto para realização desse artigo foi elaborada para identificar a influência que os líderes têm no comportamento organizacional da sua equipe. Com esta pesquisa pode-se identificar os estilos e o comportamento organizacional da empresa pesquisada.

(2002, p. 44) "é desenvolvida com base em material já elaborado, constituído principalmente de livros e artigos científicos", caracteriza-se como de natureza descritiva que ainda segundo o autor tem como finalidade primordial "a descrição das características de 
determinada população ou fenômeno ou, então, o estabelecimento de ralações entre variáveis", com abordagem quantitativa e qualitativa ${ }^{5}$, o método quantitativo para Oliveira (1999) "conforme próprio termo indica, significa quantificar opiniões, dados, nas formas de coleta de informações", ${ }^{\text {. A }}$ abordagem qualitativa não utiliza dados estatísticos como o meio do método de análise de um problema, não tem a pretensão de numerar ou medir unidades ou classes homogêneas. ${ }^{5}$ Foi realizado um estudo de caso, que conforme Gil (2010) consiste "no estudo profundo e exaustivo de um ou poucos objetos, de maneira que permita seu amplo e detalhado conhecimento". 7

\section{Coleta de dados}

No trabalho realizado foi utilizado como instrumento de coleta de dados um questionário estruturado contendo dez questões aplicadas aos liderados e uma entrevista estruturada contendo seis perguntas aplicadas aos líderes. Foram coletadas durante os meses de abril e maio de 2014 com o objetivo de obter maiores informações sobre a organização pesquisada. Os questionários foram encaminhados aos liderados que responderam as questões e recolhidos pelos pesquisadores, à entrevista foi realizada com perguntas já elaboradas aos líderes que responderam verbalmente. O processo ocorreu de forma natural, deixando aberto para novos questionamentos. Os dados do questionário foram tabulados através do programa Excel e as entrevistas foram analisadas pelos pesquisadores.

A empresa pesquisada foi escolhida, devido a participação da autora do projeto na Pastoral Carcerária de Montes Claros - MG, e ter acesso aos funcionários e colaboradores.

\section{RESULTADOS E DISCUSSÃO}

A pesquisa foi realizada com 22 funcionários que trabalham na empresa, entretanto 9 não quiseram ou não puderam responder a pesquisa. Sendo assim a coleta de dados foi realizada apenas com 13 funcionários, que serão apresentados em forma de gráficos.

Dos 13 funcionários pesquisados, 3 (três) são os líderes da empresa, 3 (três) são auxiliares administrativos e 7 (sete) são agentes. Aos liderados aplicou-se questionário e aos líderes, entrevista.

\section{Perfil dos Liderados}

Através da análise dos dados observa-se com o Gráfico 1 que entre os colaboradores respondentes da pesquisa $100 \%$ são do gênero feminino.

Com relação a faixa etária, o Gráfico 2 mostra que $80 \%$ dos respondentes (maioria) estão com idade entre 21 e 30 anos, os outros $20 \%$ estão 
divididos, sendo $10 \%$ com idade entre 31 e 40

anos e $10 \%$ com idade inferior ou igual a 20 anos.

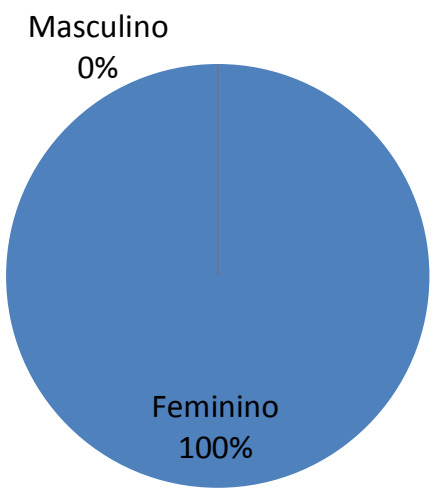

\section{Gráfico 1: Gênero}

Fonte: Pesquisa direta (2014)

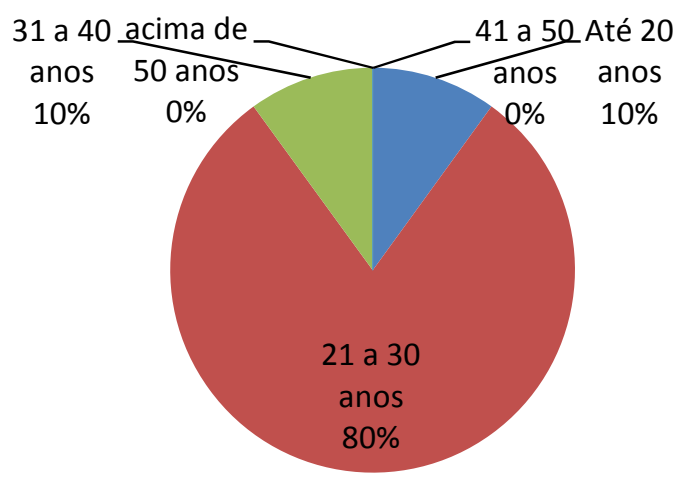

\section{Gráfico 2: Faixa Etária}

Fonte: Pesquisa direta (2014)

Quanto ao grau de escolaridade, metade dos funcionários $(50 \%)$ possui ensino superior incompleto, $30 \%$ possuem ensino médio completo e os $20 \%$ restantes dividem-se em igual porcentagem entre os que possuem ensino superior completo e os que possuem curso técnico. Não houve porcentagem para escala de pós-graduação como mostra o Gráfico 3.

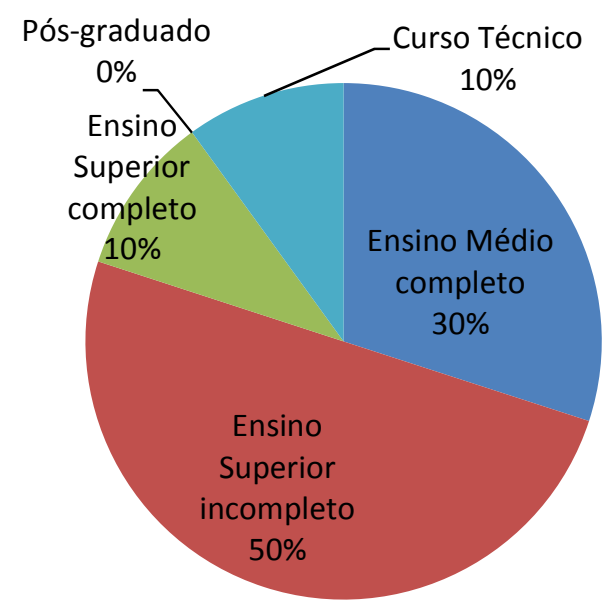

Gráfico 3: Grau de Escolaridade Fonte: Pesquisa direta (2014)

O Gráfico 4, demonstra que grande parte dos pesquisados $(70 \%)$ estão na empresa por tempo inferior ou igual a um ano de serviço, seguidos de $20 \%$ que estão na empresa a mais de 3 anos e de $10 \%$ que tem tempo de serviço entre 2 a 3 anos.

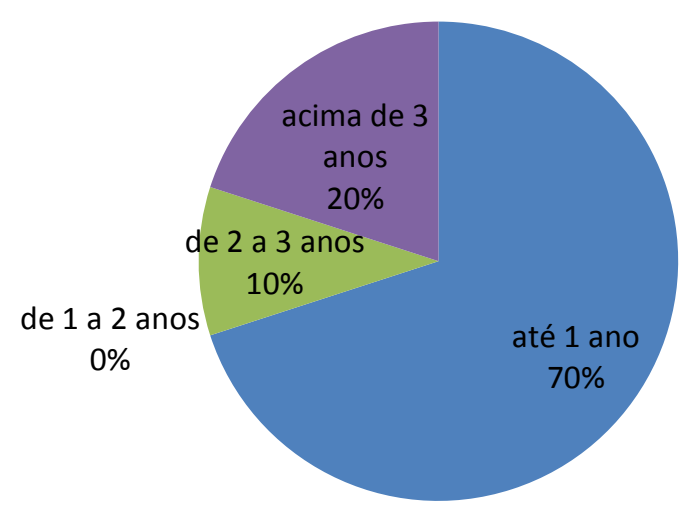

Gráfico 4: Tempo de Serviço na Empresa Fonte: Pesquisa direta (2014) 
O Gráfico 5, apresenta a avaliação das práticas adotadas pelo líder com relação ao trabalho desenvolvido em equipe. Para 50\% dos entrevistados as práticas adotadas são pouco estressante, $30 \%$ acham nada estressante, $20 \%$ acham muito estressante e nenhum respondente avaliou a prática como extremamente estressante.

De acordo com Robbins (2002) o papel desempenhado por um líder de equipe difere-se do papel de uma liderança tradicional. Esses líderes precisam desenvolver técnicas como a paciência para trocar informações, confiar nas outras pessoas, saber quando usar autoridade e qual o momento certo para intervir. ${ }^{8}$ Para o autor, líderes eficazes dominam a prática de quando deixar a equipe agir sozinha e quando intervir. Na visão de metade dos funcionários os líderes adotam práticas pouco estressantes, o que quer dizer que eles estão em busca da eficácia do desempenho da equipe, ou seja, estão revisando seus papéis e ao invés de adotar práticas de comando e controle, estão procurando agir como agentes facilitadores, ensinando as equipes tudo o que sabem e no momento certo intervindo ou deixando que elas tomem suas próprias decisões.

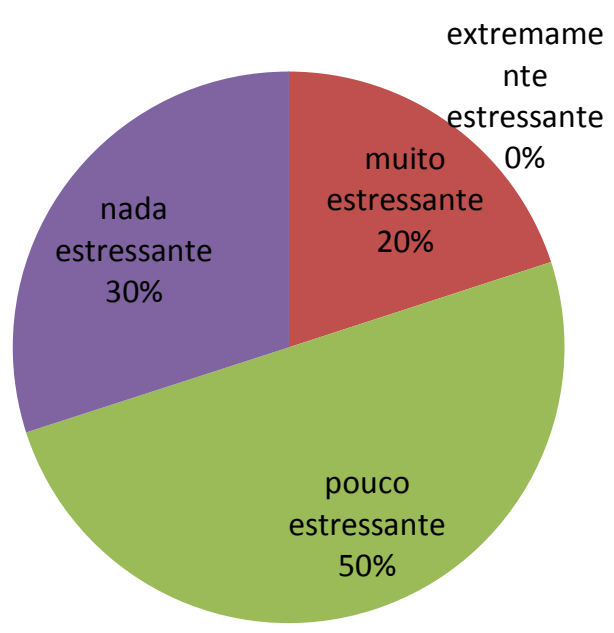

Gráfico 5: Avaliação das práticas adotadas pelo líder. Fonte: Pesquisa Direta

O Gráfico 6, permite a análise dos dados com base na avaliação feita pelos respondentes quanto ao estilo de liderança existente na empresa. Nota-se que $70 \%$ consideram o estilo de liderança adotado pelo líder como participativo, $20 \%$ consideram o estilo adotado como consultivo e $10 \%$ acreditam que o líder adota o perfil autoritário benevolente.

Os estilos de liderança relacionam-se ao comportamento dos líderes diante de seus subordinados, a forma como eles lideram. Vários são os estilos de liderança, mas não se pode dizer que um seja melhor que outro, ou que haja apenas um estilo mais adequado. Isso porque, um dos componentes das organizações são as pessoas e de acordo com Vergara (2000) elas são dotadas de uma riqueza e complexidade que dinamizam a vida da organização. Através das respostas é possível 
observar que os líderes assumem posturas diferentes. Assim, eles têm maiores chances de identificar e lidar com as variadas formas de pensamentos, sentimentos e ações dos componentes da equipe e dessa forma alcançar os objetivos esperados. ${ }^{9}$

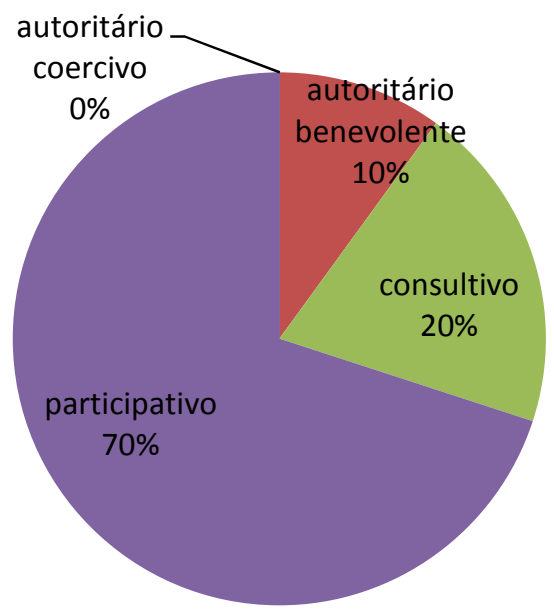

Gráfico 6: Avaliação do Estilo de Liderança Fonte: Pesquisa direta (2014)

O Gráfico 7 apresenta, na visão dos respondentes, a avaliação do comportamento organizacional da empresa. Verifica-se que $60 \%$ avaliaram o comportamento organizacional como bom, $30 \%$ avaliaram como regular e $10 \%$ avaliaram como ruim. Nenhum respondente avaliou como ótimo ou excelente. Segundo Robbins (2002) o comportamento organizacional trata-se de uma área específica para investigar o impacto que pessoas, equipes e a estrutura têm sobre o comportamento nas organizações com a intenção de utilizar o resultado alcançado para melhorar a eficácia da organização. ${ }^{8}$ Se a maioria dos entrevistados avaliou como bom o comportamento organizacional da empresa, isso quer dizer que a mesma tem condições de enfrentar problemas comuns, as empresas atualmente, como a globalização que pede funcionários mais flexíveis, capazes de adaptar facilmente as mudanças e também as diferenças encontradas na diversidade da força de trabalho. Entretanto, o fato dos entrevistados não avaliarem o comportamento organizacional como ótimo ou excelente, sugere que a empresa precisa reavaliar suas ações.

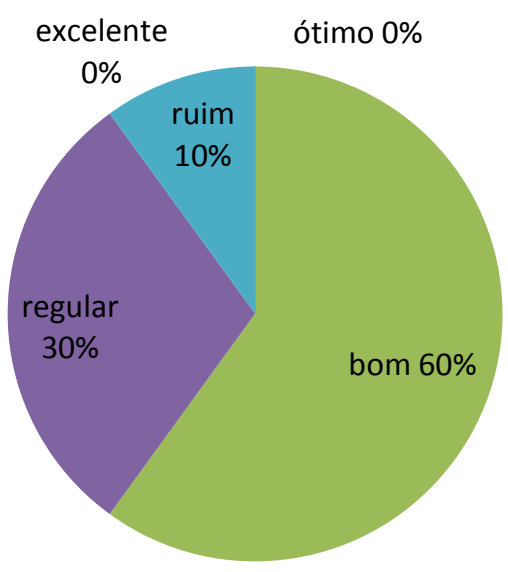

\section{Gráfico 7: Avaliação do Comportamento Organizacional da Empresa}

Fonte: Pesquisa direta (2014)

Quanto a importância do papel do líder na empresa observa-se através do Gráfico 8 que $70 \%$ dos entrevistados avaliaram como sendo importante, $20 \%$ pouco importante, $10 \%$ muito importante e nenhum acredita não ser nada importante. 
O papel do líder na empresa foi avaliado pela maioria como importante, conclui-se através dessa porcentagem que os respondentes conhecem e valorizam os esforços dos líderes para motivá-los e direcioná-los a alcançar situações de sucesso e reconhecimento tanto para a empresa, quanto para os colaboradores.

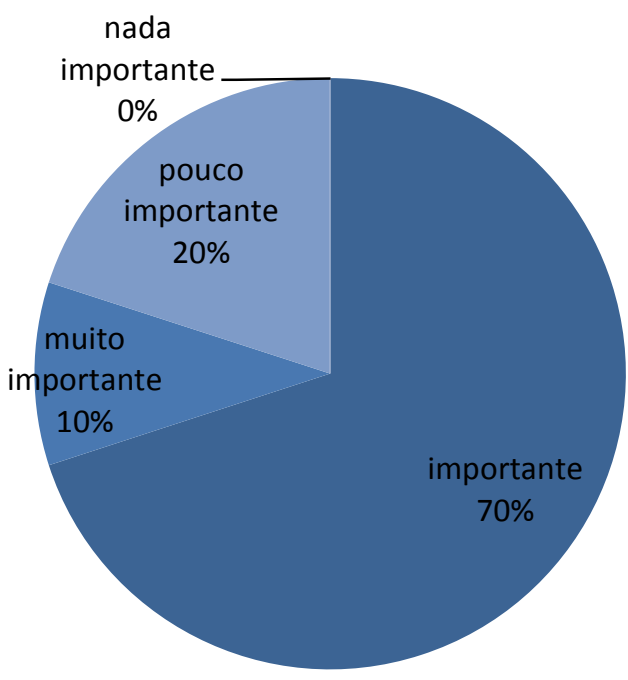

Gráfico 8: Avaliação do papel do Líder na Empresa Fonte: Pesquisa direta (2014)

De acordo com o Gráfico 9, observa-se a influência do líder no comportamento da equipe. Para $70 \%$ dos respondentes, a influência acontece sim, 30\% dizem que a influência acontece às vezes.

Quando questionados sobre o principal agente motivador utilizado pelo líder, o Gráfico 10 aponta que a maioria (40\%) respondeu ser o salário, $30 \%$ relataram outros aspectos exemplificando as folgas, $20 \%$ consideram os elogios recebidos, $10 \%$ consideram bônus e nenhum dos respondentes acredita que o exemplo dado pelo líder seja agente motivador.

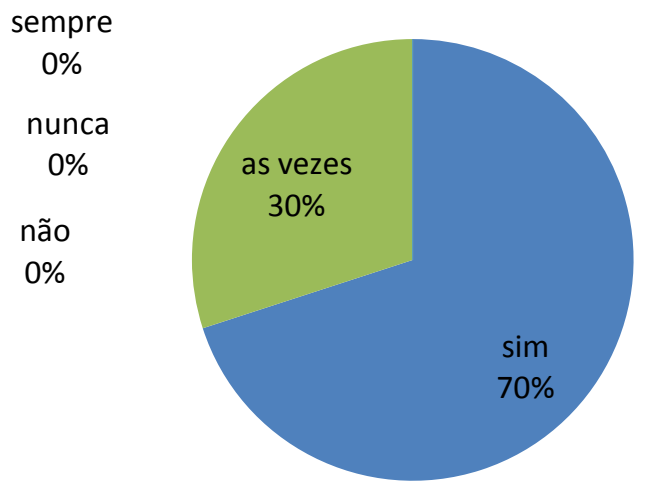

Gráfico 9: Avaliação da influência do líder no comportamento da equipe.

Fonte: Pesquisa direta (2014)

A recompensa é uma das formas que as organizações utilizam para satisfazerem algumas necessidades que seus funcionários têm em relação ao trabalho que desempenham, 9 De acordo com Newstrom (2008) as recompensas estão associadas a dinheiro. Para o funcionário é importante, pois proporciona a aquisição de bens e serviços e pode lhe oferecer status. Mas segundo o mesmo autor o dinheiro é uma recompensa extrínseca que possui limitações e pode não satisfazer todas as necessidades de uma pessoa psicologicamente saudável. ${ }^{10}$ Nesse caso, Griffin; Moorhead (2006) aconselham que as empresas analisem sua capacidade de remunerar os funcionários conforme suas condições econômicas, observando também a relação entre desempenho e recompensa. Assim os 
funcionários entenderão que suas recompensas dependerão de seus desempenhos. ${ }^{9}$ Certo (2003) defende a utilização de outras práticas motivacionais que podem manter os funcionários motivados e que não sejam financeiras, como oportunidades de promoção, que não compromete as condições econômicas da empresa. ${ }^{11}$

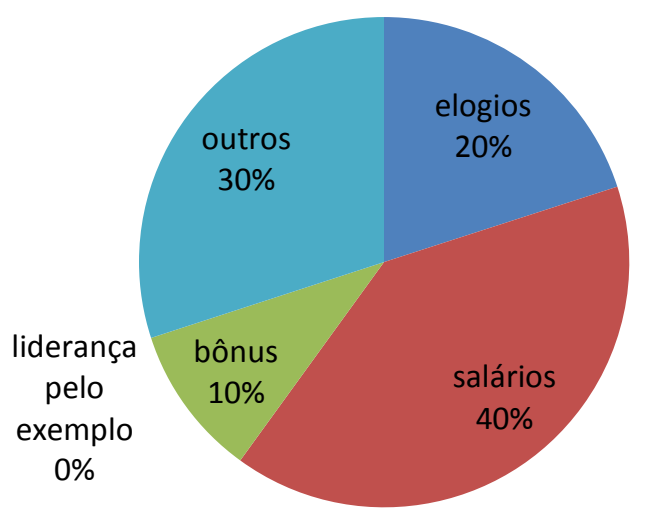

Gráfico 10: Avaliação do agente motivador utilizado pelo líder.

Fonte: Pesquisa direta

\section{Entrevista com os líderes da empresa}

Essa entrevista foi realizada com 3 líderes da empresa sobre o estilo de liderança dos mesmos.

Inicialmente foi perguntado aos líderes se eles acham importante o papel do líder dentro da empresa. Os três concordaram que sim. Segundo eles a organização só funciona de forma correta quando tem um líder que possa direcionar, guiar a equipe na busca para atingir as metas.

Segundo o que afirma Robbins (2010) esses líderes estão certos, pois "no mundo dinâmico de hoje, precisamos de líderes que desafiem o status quo, criem visões de futuro e sejam capazes de inspirar os membros da organização a querer realizar essas visões". ${ }^{12}$

Posteriormente os líderes foram questionados sobre o estilo de liderança adotado por eles, se era autoritário coercivo, autoritário benevolente, consultivo, participativo. De acordo com as respostas percebe-se que na organização os estilo de liderança são diferentes.

A liderança está diretamente associada às pessoas. Pessoas são um dos elementos que compõem as organizações, entretanto elas podem desenvolver anseios, valores, crenças, hábitos, costumes diferentes e muitas vezes o que satisfaz e motiva uma pessoa difere do que satisfaz e motiva outra. Para Cury (2009) não é preciso que o líder tenha regras, mas sim que possua bons métodos para compreender situações sociais que o possibilite agir no momento certo, assim a solução aparece de forma natural a partir da análise feita do ambiente. Dessa forma, se os líderes entrevistados adotarem posturas fixas e rígidas, podem não obter os resultados esperados.

Quando questionados se o comportamento organizacional poderia 
influenciar na equipe de funcionários, a resposta dos três líderes foi unânime, todos acreditam que sim. De acordo com um dos líderes "quando sabemos e entendemos o meio e os passos com quem trabalhamos é mais fácil corrigir os erros e melhorar os acertos" e de fato. Para Robbins (2002) umas das características do comportamento organizacional é a previsibilidade, uma vez que as pessoas são diferentes, mas em certas situações costumam reagir todas de uma mesma maneira e nesse momento é que se pode identificar consistências fundamentais que sustentam o comportamento humano e permitem a previsibilidade e que de acordo com as necessidades podem ser modificadas. ${ }^{8}$

Ao questionar como é a reação dos liderados ao receberem ordens, os líderes responderam que pelo fato de terem uma relação amigável, eles normalmente recebem da melhor forma, buscando sempre desempenhar conforme as orientações desejadas pela empresa.

Nota-se que os líderes têm conseguido desenvolver seus papéis de forma positiva na organização, visto que, a maioria dos liderados acatam de forma pacífica as ordens recebidas, alcançando assim os propósitos de um líder, que segundo Robbins (2010) diz respeito à capacidade de influenciar pessoas na realização de objetivos. ${ }^{13}$
Para finalizar, os líderes foram perguntados sobre o que fazem para conseguir uma equipe motivada. As práticas adotadas segundo eles são incentivos financeiros, diálogo e discussões ajudando a diminuir conflitos para proporcionar um ambiente mais agradável e sem stress.

Segundo Stepanski e Costa (2012) ações como essas são uma grande vantagem competitiva nos tempos atuais, pois incentivam o comprometimento organizacional, os profissionais passam a conhecem os valores da organização e sabem agir de acordo com esses valores. Assim o nível de motivação aumenta e não dependerá apenas de salários elevados e de benefícios distribuídos. ${ }^{14}$

\section{CONCLUSÃO}

Conforme exposto durante o trabalho, um líder pode assumir diferentes estilos de liderança. $\mathrm{O}$ embasamento teórico possibilitou um conhecimento maior acerca do tema. A entrevista aos líderes e o questionário aos liderados possibilitou atingir os objetivos geral e específicos, pois foi possível conhecer o perfil dos funcionários, compreender a importância do papel do líder dentro da empresa, conhecer qual o estilo de liderança exercido e também compreender o comportamento organizacional da empresa. 
Dentre os pesquisados todos são do gênero feminino, a maioria encontra-se em idade entre 21 e 30 anos. Quanto ao nível de escolaridade metade dos entrevistados possui ensino superior incompleto e nenhum deles possui pós-graduação. Com relação ao tempo de serviço que os entrevistados ocupam, a maioria está no cargo por tempo inferior ou igual a um ano.

Os funcionários foram questionados sobre alguns aspectos relacionados a seus líderes. No que diz respeito às práticas adotadas pelos líderes em relação ao trabalho desenvolvido pela equipe, metade dos funcionários avaliaram como pouco estressante. Outo aspecto que envolve o tipo de liderança adotado na empresa, as respostas variaram, mas a maioria dos respondentes acredita ser o participativo, mais conhecido como democrático. Merece destaque o aspecto sobre o comportamento organizacional da empresa, onde a maioria dos funcionários avaliou como bom e nenhum avaliou como ótimo ou excelente. Por isso, recomenda-se uma maior atenção por parte dos líderes, para que possam alcançar o êxito da equipe e da organização. Quanto à importância do papel do líder na organização, observa-se que a maioria dos entrevistados avaliou como tendo alguma importância, nenhum acredita não ser importante.
E para finalizar sobre a opinião dos funcionários, outro aspecto questionado relaciona-se ao agente motivador utilizado pelo líder. Para os respondentes são usadas ações como salário, folgas e outros, como elogios recebidos.

A partir das respostas dos empregados, pode-se concluir que a forma como os líderes atuam é satisfatória, embora haja pontos que possam ser melhorados, como o comportamento organizacional e os fatores motivacionais.

Conhecendo a opinião do liderados, observou-se a necessidade de conhecer também a opinião dos líderes.

A entrevista realizada demonstrou que os líderes acham importante a função exercida por eles dentro da organização, pois possibilita direcionar os liderados ao alcance das metas. Nesse aspecto, as informações de líderes e liderados coincidem.

$\mathrm{Na}$ empresa os líderes adotam estilos de liderança diferentes, sendo eles o participativo, situacional e o autoritário benevolente.

Os líderes acreditam que o comportamento organizacional da empresa pode influenciar na equipe. É importante frisar que apesar de eles acharem importante, os funcionários não avaliaram o comportamento organizacional como muito bom ou excelente, ou seja, ainda tem o que melhorar. Dessa forma, sugere-se aos líderes que avaliem esse 
aspecto e observe o que pode ser feito para melhorar.

Ao serem questionados sobre como os liderados recebem as ordens dadas por eles, à resposta foi que na maioria das vezes eles (liderados) reagem de forma positiva, procurando sempre atender as orientações dadas pela empresa.

E por fim, foram questionados sobre o que fazem como líderes para manter a equipe motivada. As práticas adotadas segundo eles são incentivos financeiros, diálogo e discussões com a finalidade de sanar dificuldades encontradas pelas equipes.

A pesquisa mostrou que não existe um estilo de liderança melhor que o outro, mas que depende da organização e do contexto em que está inserido. As pessoas envolvidas na organização não reagem da mesma maneira quando surpreendidas por algum acontecimento diferente em suas vidas profissional ou pessoal. O papel do líder é importante para que as organizações consigam destacar no mercado competitivo, já que os líderes sabem como direcionar os envolvidos a alcançar os objetivos pretendidos.

Percebe-se que com os resultados alcançados, mediante a pesquisa, apontam a necessidade de mais estudos, que verifiquem a ação desses fatores no dia-a-dia. Portanto, sugere-se que outras pesquisas sobre o tema sejam feitas na empresa com a função de aprofundar mais sobre o tema, de modo que possa contribuir para uma melhor relação entre líderes e liderados e assim alcançar os resultados esperados pela empresa.

\section{REFERÊNCIAS}

1. ROBBINS, Stephen

P. Comportamento organizacional. 11.ed. São Paulo: Pearson, 2005. $536 \mathrm{p}$

2. ROBBINS, Stfephen Paul. Fundamentos do Comportamento Organizacional. 8. Ed. São Paulo; Pearson Prentice Hall, 2009. 316 p

3. CHIAVENATO, Idalberto. Recursos humanos. 5. ed. São Paulo: Atlas, 1998. $623 \mathrm{p}$.

4. MAXIMIANO, Antônio Cesar Amaru. Introdução à administração. 6. ed. São Paulo: Atlas, 2004. 434 p

5. GIL, Antônio Carlos. Como elaborar projetos de pesquisa. 4 . ed. São Paulo: Atlas, 2002. 175 p.

6. OLIVEIRA, Silvio Luiz de. Tratado de metodologia científica: projetos de pesquisas, TGI, TCC, monografias, 
dissertações e teses. São Paulo:

Pioneira, 1999. $320 \mathrm{p}$

11. NEWSTROM, John W. Comportamento Organizacional: O Comportamento Humano

7. GIL, Antônio Carlos. Como elaborar projeto de pesquisa. 5 ed. São Paulo: no Trabalho. São Paulo: Ed. McGraw-Hill, 2008.

Atlas, 2010. 184 p.

12. CERTO, Samuel C. Administração

8. ROBBINS, Stephen P., moderna. 9.ed. São Paulo: PrenticeComportamento organizacional. 9 . Hall, 2003

ed. São Paulo: Prentice Hall, 2002. 637 p.

13. ROBBINS, Stephen P. Comportamento Organizacional. 14 ed. São Paulo: Pearson Prentice Hall, 2010.

e relatórios de pesquisa em administração. 3. ed. São Paulo: Atlas, 2000.

10. GRIFFIN, Ricky w; MOORHEAD, Gregory. Comportamento

14. STEPANSKI, Isabel. COSTA, Maria Eugênia. Aspectos Comportamentais da Gestão de Pessoas. Curitiba: IESDE Brasil S.A., 2012

Organizacional. São Paulo. Ática. 2006. 